\title{
A rapid and sensitive enzyme-linked immunosorbent assay (ELISA) method and validation for progestogen multi-residues in feed
}

\author{
C.-F. Peng', Y.-W. Chen ${ }^{2}$, H.-Q. Chen ${ }^{1}$, Ch.-L. Xu ${ }^{1,3}$ and Z.-Y. Jin ${ }^{1,3}$ \\ ${ }^{1}$ School of Food Science and Technology, Southern Yangtze University \\ Wuxi 214122, P.R. China \\ ${ }^{2}$ Jiangsu Institute of Nuclear Medicine \\ Wuxi 214063, P.R. China
}

(Received 10 October 2007; revised version 17 March 2008; accepted 24 June 2008)

\begin{abstract}
Some progestogens as anabolic steroids can be illegally used for increasing the efficiency of animal food production. The aim of the study was to develop convenient screening method against progestogens in feed. A sensitive enzyme-linked immunosorbent assay (ELISA) method was developed and optimized. The ELISA method is class-specific for four relative progestogens and the $\mathrm{IC}_{50}$ of the method was $3.0 \mu \mathrm{g} / 1$ for MPA. A simple feed pre-treatment method was developed for analysis progestogen residues in feed. The limits of detection (LOD) were $2.0 \mu \mathrm{g} / \mathrm{kg}$ for MPA, 5.0 $\mu \mathrm{g} / \mathrm{kg}$ for CMA, $4.6 \mu \mathrm{g} / \mathrm{kg}$ for MEGA and $3.9 \mu \mathrm{g} / \mathrm{kg}$ for HPA in the feed. The recovery was between 72.1 and $95.4 \%$ and the coefficients of variation (CV) were 7.2 to $15.8 \%$. The results have showed the simple sample pre-treatment method was suitable for progestogen multi-residues rapid analysis in feed.
\end{abstract}

KEY WORDS: progestogens, multi-residues, ELISA, feed

\section{INTRODUCTION}

Synthetic progestogens are able to stimulate other anabolic steroids likeoestradiol and increase the efficiency of animal production, e.g., medroxyprogesterone acetate (MPA), melengestrol acetate (MGA), megestrol acetate (MEGA),

\footnotetext{
* Supported by the National Natural Science Foundation of China (20675035) and 11th Five Years Key Programs for Science and Technology Development of China (2006BAK02A09 and 2006BAK02A19)

${ }^{3}$ Corresponding author: e-mail: zjin@jiangnan.edu.cn; xcl@jiangnan.edu.cn
} 
chlormadinone acetate (CMA) and 17 $\alpha$-hydroxyprogesterone acetate (HPA), etc. The use of anabolic steroids has been banned using as a growth promoter for animal food producing in many countries include China. But commercial or other benefits still stimulate people to apply them in cocktail or alternately. Thus a method for progestogen multi-residues analysis is necessary. ELISA method has been demonstrated as a simple, rapid, and cost-effective alternative to those traditional methods in cases where high-throughput and/or on-site screening are needed. Although some specific ELISA method for progestogens, MGA (Hageleit et al., 2001), MPA (Lewis et al., 1992; Peng et al., 2006b) and HPA (Guizhen et al., 1988), and some specimen, serum (Lewis et al., 1992), fat and muscle tissues (Rosen et al., 1994; Hageleit et al., 2001; Peng et al., 2006a) and liver (Peng et al., 2006b) have been reported, no special discussion about analysing these compounds in feed specimen were found. The applied antibody was prepared to develop simple and class-specific ELISA method for analysing some progestogen muti-residues in feed here.

\section{MATERIAL AND METHODS}

\section{Chemicals and instruments}

Reagents were obtained from the following sources: MPA, MGA and 3,3',5,5'Tetramethlbenzidine (TMB) (Sigma-Aldrich, Germany); CMA, MEGA, HPA, hydrocortisol, progesterone, hydrocortisone and 19-Nortestosterone (Taizhou Baida Pharmaceutical Co., Ltd., China); horseradish peroxidase - labeled antimouse immunoglobulin rabbit IgG ((HRP-anti-IgG) (Rockland Immunochemicals, Inc., USA), acetonitrile, ethyl acetate, tert-butyl methyl ether (TBME) and hexane (Merk, Germany, HPLC grade). Coating antigens 3-CMO-MPA-OVA and antiMPA antiserum were prepared by our laboratory. All other reagents were of analytical grade. The ELISA was carried out in 96-well polystyrene microtiter plates (Costar sripwell plate 2592, China).

\section{Buffers and solutions}

The buffers used regularly were: a. coating buffer; $50 \mathrm{mmol} / 1$ carbonate buffer (pH 9.5), b. phosphate buffered saline (0.01 M PBS), $10 \mathrm{mmol} / 1$ sodium phosphate buffer (pH 7.4) containing $140 \mathrm{mmol} / \mathrm{l} \mathrm{NaCl}$, c. dilution buffer, PBS containing $0.1 \%(\mathrm{w} / \mathrm{v})$ gelatin, $\mathrm{d}$. washing buffer $(\mathrm{PBST}), 10 \mathrm{mmol} / 1$ sodium phosphate buffer ( $\mathrm{pH}$ 7.4) containing $140 \mathrm{mmol} / 1 \mathrm{NaCl}$ and $0.02 \%(\mathrm{v} / \mathrm{v})$ Tween 20, e. blocking buffer, PBS containing $1 \%(\mathrm{w} / \mathrm{v})$ OVA, and f. substrate solution; $50 \mathrm{mmol} / \mathrm{l}$ sodium citrate buffer ( $\mathrm{pH} 5.0$ ) containing $0.01 \%(\mathrm{w} / \mathrm{v}) \mathrm{TMB}$ and $0.005 \%(\mathrm{v} / \mathrm{v}) \mathrm{H}_{2} \mathrm{O}_{2}$. 


\section{Indirect competitive ELISA}

The concentrations of coating antigens, antibodies and enzyme tracer (HRPanti-IgG) were selected by checkerboard titration. Afterward a set of experimental parameters (incubation time, ionic strength, $\mathrm{pH}$ and detergent concentration) was studied. The optimal ELISA method protocol as follows: polystyrene 96-well microplates were coated with $100 \mu \mathrm{l} /$ well of MPA-OVA conjugates $\left(0.1 \mu \mathrm{g} \mathrm{ml}^{-1}\right)$ in coating buffer overnight at $4^{\circ} \mathrm{C}$ and blocked for $2 \mathrm{~h}$ at $37^{\circ} \mathrm{C}$. Serial dilutions of the progestogen standards in PBST (from 0.05 to $50{\mu \mathrm{gl}^{-1}}^{-1}$ ) were added into the sensitized microplate $(50 \mu \mathrm{l} /$ well $)$, followed by the appropriately diluted antiserum $(1 / 5000$ in dilution buffer, $50 \mu \mathrm{l} / \mathrm{well}$ ). After incubation at RT for $60 \mathrm{~min}$, the plates were washed three times with PBST and patted dry. The appropriately diluted AntiIgG-HRP (1/5000 in dilution buffer) was then added (100 $\mu \mathrm{l} /$ well) and incubated for $30 \mathrm{~min}$ at RT. After a wash procedure again, the substrate solution was added $(100 \mu \mathrm{l} /$ well). Colour development was continued and stopped after $15 \mathrm{~min}$ at RT with $2 \mathrm{M} \mathrm{H}_{2} \mathrm{SO}_{4}$, and the absorbances were read at $450 \mathrm{~nm}$ by a Thermo MK3 microplate reader (Thermo Electron, China). Competitive curves were obtained by plotting absorbance against the logarithm of analyte concentration.

\section{Characterization of the ELISA method}

Nine steroid compounds (MPA, CMA, MEGA and HPA, MGA, progesterone, hydrocortisone, diethylstilbestrol and 19-Nortestosterone), which are structurally homogeneous or related, were selected for specific evaluation of the ELISA method.

Stock solutions of $0.1 \mathrm{mg} / \mathrm{ml}$ of them in methanol were prepared for serial standard solution. Standard curves for each of these compounds were constructed ( 0.2 to $200 \mu \mathrm{g} / 1$ in PBST) and their $\mathrm{IC}_{50}$ values were determined for cross-reactivity calculation. The cross-reactivity (CR) was calculated according to the following equation:

$$
\text { Cross-reactivity } \%=\frac{\text { Standard } \mathrm{IC}_{50}}{\text { Cross-reactant }_{\mathrm{IC}}} \times 100
$$

\section{Sample pre-treatment and validation}

The pig and fish feed were ground to powder with a glass pestle. Each sample of $2 \mathrm{~g}$ in a tube was spiked with 10,20 or $40 \mu \mathrm{l}$ of $1.0 \mu \mathrm{g} / \mathrm{ml}$ MPA standard solution in methanol, respectively. And another series of blank samples of $2 \mathrm{~g}$ each were spiked with 20,40 or $80 \mu \mathrm{l}$ of $1.0 \mu \mathrm{g} / \mathrm{ml} \mathrm{CMA,} \mathrm{MEGA} \mathrm{or} \mathrm{HPA} \mathrm{standard} \mathrm{solution} \mathrm{in}$ methanol. These give the specimen equivalent concentration of 5,10 and $20 \mu \mathrm{g} / \mathrm{kg}$ 
MPA and another one of 10, 20 and $40 \mu \mathrm{g} / \mathrm{kg}$ CMA, MEGA or HPA. Ten $\mathrm{ml} 20 \%$ methanol solution in $0.1 \mathrm{M}$ carbonate buffer was applied into it and homogenized for $1 \mathrm{~min}$ at 10,000 rpm. Five ml TBME was then added and mixed by a vortex for $1 \mathrm{~min}$. The tube then stood in a supersonic bath for $10 \mathrm{~min}$ till the emulsified phase was broken. The mixture was then centrifuged at $3000 \mathrm{~g}$ for $10 \mathrm{~min}$ and $5 \mathrm{ml} \mathrm{TBME}$ phase was decanted. Afterward solvent was dried under nitrogen at $40^{\circ} \mathrm{C}$ the residue was reconstituted in $10 \mathrm{ml}$ PBST buffer by vortex for ELISA analysis. The accuracy was evaluated by determining the recovery of spiked standards in 5 parallel samples. The precision was evaluated by determining the relative standard deviation (RSD) 15 samples totally in 3 days ( 5 samples each day).

\section{RESULTS AND DISSCUSION}

Characterization of the ELISA method. Under optimum physico-chemical conditions, the ELISA for MPA reported here has an $\mathrm{IC}_{50}$ of $3.0 \mu \mathrm{g} / 1$, the working range $\left(80-20 \%\right.$ of the $\left.A_{\max }\right)$ is placed between 0.3 and $30 \mu \mathrm{g} / 1$. The $A_{\max }$ of the assay was always more than 1.0 units of absorbance.

Results showed (Table 1) that the antibody had high cross-reactivity with CMA (39.5\%), MEGA (56.6\%) and HPA (62.5\%), but no cross-reactivity with other steroids (the $\mathrm{IC}_{50}$ of the five steroids can't be evaluated). As screening method of veterinary drug residue, specific for four progestogens will be more useful than one when several veterinary drug need to be inspected.

Table 1. Cross reactivity and LODs of four progestogens in pig feed $(n=10)$

\begin{tabular}{lcccc}
\hline Parameters & MPA & CMA & MEGA & HPA \\
\hline IC50, $\mu \mathrm{g} / 1$ & 3.0 & 7.6 & 5.3 & 4.8 \\
CR, $\%$ & 100 & 39.5 & 56.6 & 62.5 \\
LOD, $\mu \mathrm{g} / 1$ & 2.0 & 5.0 & 4.6 & 3.9 \\
R.S.D., $\%$ & 5.6 & 7.3 & 6.4 & 7.7 \\
\hline
\end{tabular}

Sample pre-treatment. Feed sample was pretreated in alkaline buffer and $20 \%$ methanol and then partitioned by tert-butyl methyl ether (TBME), which could reserve most of polar impurity in the buffer and increase the selectivity of TBME extraction. Supersonic could not only break emulsification, but also ensure sufficient extraction and decrease variation of extraction. Nevertheless, the matrix effect was still very notable (Figure 1). After the matrix was diluted by ten times, the effect of it could be decreased mostly. Through matrix addition to the standard solution, the calibration curve could be used to measure the progestogens residue quantitatively.

Two different feed, pig and fish diet, were investigated to compare the difference of different matrix. Figure 2 showed that matrix effect of the pig feed was slightly 
lower than that of the fish. Followed by dilution times of the two kinds of matrix increasing, the maximal signal $\left(\mathrm{A}_{\max }\right)$ increased step by step. Figure 2 shows that $10 \%$ matrix has been suitable for the ELISA analysis.

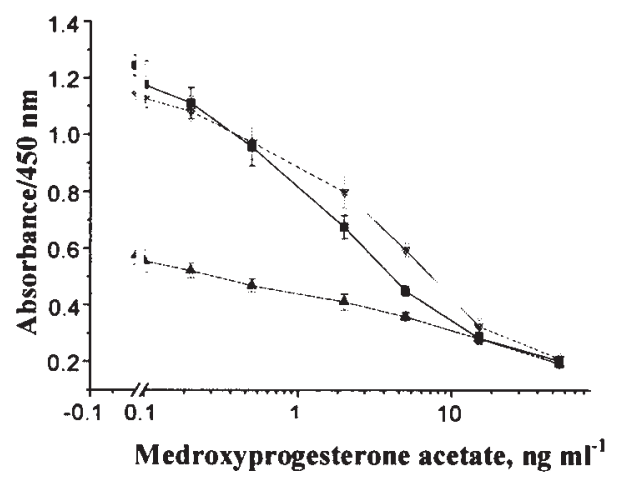

Figure 1. Effect of feed matrix on standard curve of MPA. MPA santandard curve in the PBS ( $\mathbf{})$, in feed matrix diluted $1 / 10$ with $\operatorname{PBS}(\boldsymbol{\nabla})$, and in neat feed matrix $(\boldsymbol{\Delta})(\mathrm{n}=5)$

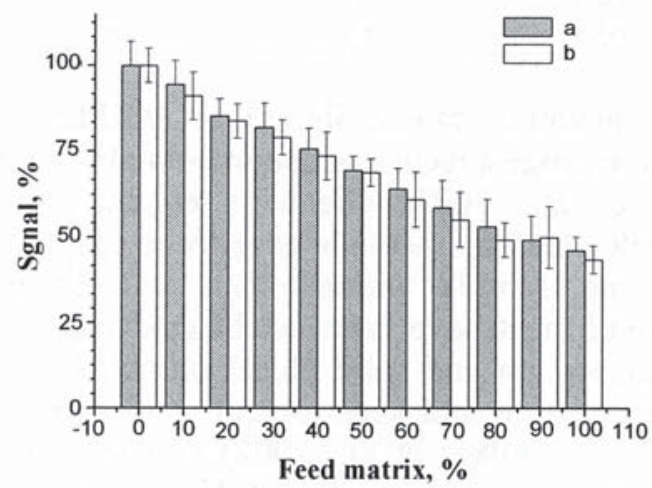

Figure 2. Effect of feed matrix on maximum absorbance of the assay for MPA: a and b represent pig feed and fish feed, respectively. Each point represents the mean value of triplicate measurements $(n=5)$

Validation. The limits of detection (LOD) were calculated by taking the mean value of 10 blank samples plus 3 times of standard deviations of the mean. The LODs were calculated to be $2.0 \mu \mathrm{g} / \mathrm{kg}$ for MPA, $5.0 \mu \mathrm{g} / \mathrm{kg}$ for CMA, $4.6 \mu \mathrm{g} / \mathrm{kg}$ for MEGA and $3.9 \mu \mathrm{g} / \mathrm{kg}$ for HPA in pig feed after blank pig feed samples were determined (Table 1).

The recoveries of the four progetagens were also determined, which could be used to compensate work-up losses. The results were shown in Table 2. It could be 
found the recoveries for them were between 75.0 and $92.1 \%$ at three concentration levels for pig feed, and between 72.1 and $95.4 \%$ for fish feed. The relative standard deviations (RSD) were 8.2 to $15.8 \%$ for pig feed, and 7.2 to $15.5 \%$ for fish feed.

Table 2. Inter-day precision and accuracy for progestogens using developed ELISA

\begin{tabular}{|c|c|c|c|c|c|}
\hline \multirow[b]{2}{*}{ Analytes } & \multirow[b]{2}{*}{$\begin{array}{c}\text { Spiked } \\
\text { level } \\
\mu \mathrm{g} / 1\end{array}$} & \multicolumn{2}{|c|}{ Pig feed } & \multicolumn{2}{|c|}{ Fish feed } \\
\hline & & $\begin{array}{c}\text { accuracy } \\
\text { recovery, } \% \\
n=5\end{array}$ & $\begin{array}{c}\text { inter-day } \\
\text { precision } \\
\text { RSD, \% } \\
n=3\end{array}$ & $\begin{array}{c}\text { accuracy } \\
\text { recovery, } \% \\
n=5\end{array}$ & $\begin{array}{c}\text { inter-day } \\
\text { precision } \\
\text { RSD, \% } \\
n=3\end{array}$ \\
\hline \multirow[t]{3}{*}{ MPA } & 5 & 81.4 & 15.8 & 72.1 & 13.4 \\
\hline & 10 & 86.4 & 11.4 & 85.3 & 8.2 \\
\hline & 20 & 88.2 & 8.2 & 81.4 & 9.1 \\
\hline \multirow[t]{3}{*}{ CMA } & 10 & 75.0 & 13.1 & 80.6 & 15.5 \\
\hline & 20 & 78.9 & 8.5 & 84.9 & 9.6 \\
\hline & 40 & 77.6 & 10.7 & 86.7 & 9.5 \\
\hline \multirow[t]{3}{*}{ MEGA } & 10 & 86.5 & 15.0 & 83.8 & 10.8 \\
\hline & 20 & 90.7 & 10.9 & 86.2 & 7.2 \\
\hline & 40 & 83.1 & 12.2 & 85.7 & 9.0 \\
\hline \multirow[t]{3}{*}{ HPA } & 10 & 85.2 & 10.9 & 81.1 & 12.3 \\
\hline & 20 & 89.7 & 10.3 & 95.4 & 8.7 \\
\hline & 40 & 92.1 & 8.7 & 85.8 & 8.4 \\
\hline
\end{tabular}

Because MRLs (maximal residue limits) or MRPLs (minimum required performance limits) the progestogens residue in animal food were as low as 1 to $10 \mu \mathrm{g} / \mathrm{kg}$ (Impens et al., 2003; Giannetti et al., 2005), complex and cost-consuming sample clean-up methods have to be adapted for animal fat and meat specimen. Some sample pretreatment and clean-up methods for progestogens in fat and meat have been established including combination of matrix solid phase dispersion and solid phase extraction (Rosen et al., 1994), accelerated solvent extraction and supercritical fluid extraction for kidney fat (Stolker et al., 2002; Hooijerink et al., 2003) and most of them are solvent extraction and solid phase extraction method (Hageleit et al., 2001; Impens et al., 2002; Giannetti et al., 2005) for kidney fat or meat. Feed containing below $10 \mu \mathrm{g} / \mathrm{kg}$ progestogens is usually ineffective for bringing drug residue in animal tissues, because most of progestogens will be metabolized. Although the simple extraction and standard calibration method for feed developed here have higher coefficients of variation than clean-up method for animal tissues, it still can meet the need for rapid screening progestogens residue in feed.

To further demonstrate reliability of the ELISA method for determination of progestogen residues in feed, 10 pig feed samples and 10 fish samples from local market were analysed using the ELISA method and LC/MS/MS method. 
Medroxyprogesterone acetate (MPA) was found in three fish feed samples. The MPA concentrations are presented in Table 3. Compared with the results from LC/MS/ MS, the MPA concentrations were consistently higher. This result of overestimating the analyte concentration was probably due to the matrix interference from other steroids and lipids in the ELISA method. The reason need further study in the future.

Table 3. MPA and CMA concentration in feed samples collected from local markets $(n=3)$

\begin{tabular}{lcc}
\hline \multirow{2}{*}{ Sample } & \multicolumn{2}{c}{ MPA, $\mu \mathrm{g} / \mathrm{kg}$, mean \pm SD } \\
\cline { 2 - 3 } & ELISA & LC/MS/MS \\
\hline 1 & $5.9 \pm 0.7$ & $4.1 \pm 0.3$ \\
2 & $21.5 \pm 2.2$ & $15.3 \pm 1.2$ \\
3 & $18.7 \pm 2.0$ & $14.9 \pm 1.1$ \\
\hline
\end{tabular}

\section{CONCLUSIONS}

In conclusion, the developed ELISA method is specific for four progestogens and suitable for routine qualitative measurement of them in animal feed. The method was sensitive and the sample treatment method was also simple and costsaving. This strategy is effective in some specimen. However, livestock and aquatic animal feed all have many types and the matrix effects of them will be different for the ELISA method. Thus, the recovery and precision should be investigated when the method is applied to a new kind of feed.

\section{REFERENCES}

Giannetti L., Barchi D., Fiorucci F., Gennuso E., Sanna P., Pallagrosi M., Neri B., 2005. High-performance liquid chromatography-tandem mass spectrometry validation of medroxyprogesterone acetate in products of pork origin and serum. J. Chromatogr. Sci. 43, 333-336

Guizhen H., Hong W., Qun L., Yunhong C., 1988. An enzyme immunoassay of plasma megestrol acetate concentration in rabbits. Acta Acad. Med. Shanghai 15, 293-298

Hageleit M., Daxenberger A., Meyer H.H.D., 2001. A sensitive enzyme immnoassay (EIA) for the dtermination of melengestrol acetate (MGA) in adipose and muscle tissues. Food Addit. Contam. 18, 285-291

Hooijerink H., van Bennekom E.O., Nielen M.W.F., 2003. Screening for gestagens in kidney fat using accelerated solvent extraction and liquid chromatography electrospray tandem mass spectrometry. Anal. Chim. Acta 483, 51-59

Impens S., Courtheyn D., De Wasch K., De Brabander H.F., 2003. Faster analysis of anabolic steroids in kidney fat by downscaling the sample size and using gas chromatography-tadem mass spectrometry. Anal. Chim. Acta 483, 269-280 
Impens S., De Wasch K., Cornelis M., De Brabander H.F., 2002. Analysis on residues of estrogens, gestagens and androgens in kidney fat and meat with gas chromatography -tandem mass spectrometry. J. Chromatogr. A 970, 235-247

Lewis L.K., Elder P.A., Brrell G.K., 1992. An enzyme linked immunosorbent assay (ELISA) for plasma medroxyprogesterone acetate (MPA). J. Steroid Biochem. Mol. Biol. 42, 179-183

Peng C., Xu C., Jin Z., Chu X., Wang L., 2006a. Determination of anabolic steroid residues (Medroxyprogesterone Acetate) in pork by ELISA and comparison with liquid chromatography tandem mass spectrometry. J. Food Sci. 71, C44-C50

Peng C.F., Xu C.L., Jin Z.Y., 2006b. Comparative analysis of medroxyprogesterone acetate residue in animal tissues by ELISA and GC-MS. Anal. Lett. 39, 1865-1873

Rosen J., Hellenas K.E., Tornqvist P., Shearan P., 1994. Automated extraction of acetylgestagens from kidney fat by matrix solid phase dispersion. Analyst 119, 2635-2637

Stolker A.A.M., Zoontjes P.W., Schwillens P.L., Kootstra P.R., Van Ginkel L.A., Stephany R.W., Brinkman U.A., 2002. Determination of acetyl gestagenic steroids in kidney fat by automated supercritical fluid extraction and liquid chromatography ion-trap mass spectrometry. Analyst $127,748-754$ 